\title{
Robert Bly Alive in Darkness
}

\section{Anthony Libby}

Often self-consciously, poetry now reassumes its ancient forms. When at Antioch College in the autumn of 1970 Robert Bly began a reading with an American Indian peyote chant, he seemed merely to be accepting a hip convention almost expected by an audience accustomed to Ginsberg and Snyder. Bly chanted for the usual reason, "to lower the consciousness down, until it gets into the stomach and into the chest and farther on." But no such convention had existed in the early fifties, when Bly began to publish his intimations of physical transcendence, poetry of the mystical body, and the conventional mystical terms that have since become so easily available are still inadequate to describe what happens in his unique poetry. To use a characteristic phrase of Bly's, "something important is hidden in there that we don't understand."

Because of the elusively compelling force of its "deep images," Bly's poetry demands interpretation as much as it seems to resist it. When it does not consist of simple deliberately prosy statement, much of it seems obscure, distant, but at the same time it conveys a sense of meaning immediately perceived though seldom paraphrasable in any but its own terms. It is difficult to explain Bly's surrealist poetry, hard to say why some of his imagery moves us so basically and why some appears comparatively contrived, but undeniably his strongest poetry evokes some sort of truth all the more forceful because it exists beneath or beyond any reasoned response. However, what the stomach feels, the mind wants to know. Perhaps the best way to appreciate Bly's irrational evocations is to attempt to explain them logically. If this seems paradoxical, such paradoxes are implicit in the act of analyzing almost all poetry, not merely surrealist poetry, and in any case Bly himself provides ample precedent. Like many mystical poets he writes with large patterns in mind, and behind his explorations into darkness there stands not only a complex poetic theory but also a highly articulated scheme of the psychological development of civilization. This scheme, also like that of other mystical poets (Blake, for instance), is frequently based on logical antithesis suspended in paradox, and only through an understanding of paradoxes simple and profound can we come to terms with Bly's poetry.

He begins with the intention of creating a truly free associationalism, radically opposed to what he considers the calculated and artificially logical associationalism of Eliot and Pound. In an essay called "Looking for Dragon Smoke" he argues that the formalist obsessions of modern American poets (from Eliot to Charles Olson) have obscured the true psychic bases of poetry. "Our task is not to invent and encourage jargon about 'open form' and breath patterns, but to continue to 
open new corridors into the psyche by association." His associative and implicitly irrationalist poetry depends not on form but on imagery, primarily on the conception of the "subjective image" developed by Bly and such friends of his as William Duffy and James Wright. The successful subjective image (or "deep image") strikes us with the force of a newly discovered archetype, minor or major, coming from the depths of the poet's subjectivity with a paradoxically universal force, his private revelation made ours. In Bly's "Depression," for instance, the poet describes his psychic state in images which despite their novelty seem more discovered than made.

I dreamt that men came toward me, carrying thin wires;

I felt the wires pass in, like fire; they were old Tibetans;

Dressed in padded clothes, to keep out cold;

Then three work gloves, lying fingers to fingers,

In a circle, came toward me, and I awoke.

Like these, Bly's images are almost invariably marked by a surrealist concreteness; not only are psychological or spiritual states felt in material form, but all substances seem to seek greater density. In various poems in Silence in Snowy Fields, air frequently becomes water ("the quiet waters of the night"), darkness "drifts down like snow," snow becomes "jewels," moonlight becomes "The sound of the deaf hearing through the bones of their heads," etc. Even when this metaphorical transposition of substances could be interpreted as moving in the opposite direction, toward a reduction of density ("Waterfalls of stone deep in mountains,/ Or a wing flying alone beneath the earth") still we feel a pervasive sense of heaviness, a downward drift.

This imagery suggests the constant preoccupation of Silence; the metaphorical flow into greater concreteness reflects the spiritual movement enacted or wished for in most of the poems, a sinking into things, into the earth, usually into darkness, finally into death. Often, as Richard Howard explains in Alone with America, spiritual immersion becomes a literal immersion in water. Howard's intelligent though rhetorically somewhat convoluted introduction to Bly centers on the "latent" waters of "that Minnesota mariner," which Howard connects with "the stream the Greeks called Lethe." As Bly writes in "Return to Solitude,"

We want to go back, to return to the sea,

The sea of solitary corridors,

And halls of wild nights,

Explosions of grief,

Diving into the sea of death,

Like the stars of the wheeling Bear.

But though transcendent death by water suggests ancient mystic patterns, Bly's vision of the death which feeds life is neither exactly traditional nor really transcendental. Another main current of imagery in Silence suggests interpenetration of body and world. Animism ("The dawn stood there with a quiet gaze;/ Our 
eyes met through the top leaves of the young ash") is complemented by a sort of bodily surrealism ("Inside me there is a confusion of swallows"). As the psyche is crowded with arcane corporeal images, so the body contains the objects of the world. In the past, for instance in Thoreau, such body-world parallelism and interpenetration has been used to suggest a higher spiritual reality which penetrates all physical being. More recently, in, say, the poetry of Sylvia Plath, the same pattern of imagery has grown into a vision of all physical substance as grotesquely alien to the perceiving consciousness, the body a dead husk imprisoning a sickened spirit, things endowed with terrifying life. While obviously closer to Thoreau, Bly is essentially similar to neither. His animism stems from a perception of vitality in things which connects with the vitality in the body, but which is neither separable from states of physical being nor basically alien to consciousness. Dying into the darkness at the heart of Bly's poetry is not a transcendence of the body but an immersion in the body in turn immersed in the corporeal flow of things. If this elusive immersion is achieved, the body in its fullness contains and is contained by "the inner world," which is this world, not illuminated but condensed to its deepest indivisible essence.

So behind the traditional mystical paradox-the praise of ordinarily negative states, grief and "the death we love," as avenues to holy joy- there exists in Bly the further paradox that spiritual union with the universe must be sought in physical terms. Perhaps for this reason trees play a constant symbolic role in Silence, reaching toward emptiness, but always rooted in the earth. In "Poem in Three Parts":

The strong leaves of the box-elder tree, Plunging in the wind, call us to disappear

Into the wilds of the universe,

Where we shall sit at the foot of a plant,

And live forever, like the dust.

The dust, which appears frequently in Bly's poetry, suggests the most corporeal vision of union with the cosmos, a union spiritually more meaningful than the traditional theological dreams of death if only because of its physical inevitability. Bly compares the two visions in "At the Funeral of Great-Aunt Mary."

The minister tells us that, being The sons and daughters of God, We rejoice at death, for we go

To the mansions prepared

From the foundations of the world.

Impossible. No one believes it.

\section{III}

Out on the bare, pioneer field, The frail body must wait till dusk

To be lowered

In the hot and sandy earth. 
The sense of death as physical union with everything becomes a spiritual or moral force in life because it celebrates a loss of self into the other which is more absolute than the ego-loss presumably implied by the death of transcendence; the traditional mystic soul united with god as often seems swollen as lost in oneness. Also the sense of corporeal dissolution of self is, Bly suggests, always with us. Every sleep is a bodily premonition of death. Much of Silence concerns periods of transition between waking and sleep, between light and darkness. During such periods the deep image comes close to the surface because the mind sinks to the depths of the body, the body opens to the world.

The day shall never end, we think:

We have hair that seems born for the daylight;

But, at last, the quiet waters of the night will rise,

And our skin shall see far off, as it does under water.

Perhaps it no longer seems paradoxical that the state of "approaching sleep" is most fully described in "Awakening."

We are approaching sleep: the chestnut blossoms in the mind

Mingle with the thoughts of pain

Bodies give off darkness, and chrysanthemums

Are dark, and horses, ... .

As the great wheel turns around, grinding

The living in water.

... the living awakened at last like the dead.

In his second collection of poems, The Light Around the Body, Bly's paradoxes are deepened because much of his poetry spreads into another world. Like various other American mystics, most conspicuously Thoreau, Bly becomes interested in the politics of American imperialism, a subject at least superficially uncongenial to mysticism. All but one of the sections of Light begin with quotations from Jacob Boehme, the Protestant mystic who influenced the American transcendentalists (through Emerson, who knew him as "Behemen"). "For according to the outward man, we are in this world and according to the inward man, we are in the inward world ... Since then we are generated out of both worlds, we speak in two languages, and we must be understood also by two languages." The poems of Light concern the conflict between the two worlds, in the poet, and in America. So inevitably these poems bring together the two languages of which Boehme speaks, doubling Bly's paradoxes, sometimes confusingly. Light still praises grief and maps the progress of the body toward that death which is fulfillment, but while Silence emphasized intimations of ultimate union Light focuses on obstacles to the good death, one of which is, paradoxically, another sort of death. "Smothered by the World" describes a purgatory between life and death. 
Once more the heavy body mourns!

It howls outside the hedges of life,

Pushed out of the enclosure.

Now it must meet the death outside the death.

Living outside the gate is one death,

Cold faces gather along the wall,

A bag of bones warms itself in a tree.

This death results from basic spiritual distortion in the world. Bly describes it in the same physical terms he used to connect the body and the world, but here the connection has become grotesque. Human consciousness inhabits objects only to suggest a general despair, as in "Those Being Eaten by America."

The wild houses go on

With long hair growing from between their toes

The feet at night get up

And run down the long white roads by themselves

The dams reverse themselves and want to go stand alone in the desert

The sterile death that follows this despair is occasionally described in terms of whiteness, often snow, but even the darkness which in Silence was always the medium of visions has in Light changed, become corrupted. "There is another darkness," Bly writes in "Listening to President Kennedy Lie about the Cuban Invasion." "There is a bitter fatigue, adult and sad."

The other darkness, in poems like "Hatred of Men with Black Hair," is described as inhabiting the same deep realms as the darkness of vision.

The State Department floats in the heavy jellies near the bottom

Like exhausted crustaceans, like squids who are confused,

Sending out beams of black light to the open sea,

Both darknesses exist at the root of the mind, which is the source of politics as well as poetry. As the title of "Hatred" suggests, the destructive darkness results from a refusal to acknowledge that more primitive darkness which is the way to union. The American dream of self-proclaimed innocence, so shot through with unacknowledged blackness, leads to a death which cannot reinforce life, if only because it strikes so unnaturally. This vision is dramatized most fully in Bly's later poem "The Teeth Mother Naked at Last," but it is suggested in "At a March against the Vietnam War," which appears in Light. Bly says of "a boat/ Covered with machine guns:"

It is black,

The hand reaches out

And cannot touch it-

It is that darkness among pine boughs 
That the Puritans brushed

As they went out to kill turkeys

At the edge of the jungle clearing

It explodes

On the ground

We long to abase ourselves

We have carried around this cup of darkness

We have longed to pour it over our heads

Always, however individually, the poet reflects his time. Primarily Silence contains poetry written in the 1950's, a time of comparative political innocence (or naiveté) for American literature, when literary rebellion against America was usually considered a rather solitary and apolitical experience. Silence is a book of solitude, of Bly alone with the world; even its few love poems do not involve a recognizable other. Light is a book of the sixties, a predominantly political book, like many other books of poetry published since 1966 (the year Bly organized American Writers Against the Vietnam War). But while Bly's development must obviously be understood in terms of our recent history, he might probably have undergone similar changes in any historical context, for in Light he is only dramatizing a tension implicit in the paradoxes of Silence.

Traditionally, mysticism has existed in potential or actual conflict with more earthly approaches to morality; the conflict surfaces when the mystic theorizes about evil. Having accepted grief and the dissolution of his body as aspects of a vital flow into "the wilds of the universe," Bly must logically confront experiences of grief and death, perhaps unnecessary grief and premature death, much less palatable to those who suffer them. The mystic always returns to the world of men. The perception of dominant and perhaps inherent evil there can blunt his mystic acceptance, or it can become the basis for more strenuous efforts toward transcendence, a denial of the essential reality of certain aspects of the world in favor of higher realities. Allen Ginsberg, for instance, plays more or less seriously with the latter response when he chants, in "Wichita Vortex Sutra": "I here declare the end of the War/ Ancient days' Illusion." But because Bly's mysticism remains untranscendental ("The two worlds are both in this world") neither traditional response is really possible. The social fact of pointless death forces a deeper examination of the idea of death as a spiritual good, but Bly is unwilling to deny either vision.

What he attempts to do instead, besides suggesting how the primitive sense of union has been lost, how death has been corrupted, is to create a vision of process toward a new world in which paradoxes resolve themselves. But the approach of this world is itself paradoxical, a terrible movement toward communal death which, like the individual death of Silence, is also the approach of birth. As the tension between inner and outer worlds grows more extreme Bly suggests that the center will not hold; however the approaching apocalypse is also de- 
scribed as evolution. The final section of Light is called "A Body Not Yet Born." Like the rest of the book it contains images of despairing death, as in "Hurrying Away from the Earth."

Some men have pierced the chest with a long needle

To stop the heart from beating any more;

The time for exhortation is past. I have heard

The iron chairs scraping in asylums,

Men cry when they hear stories of someone rising from the dead.

If the dark night of the soul has become a universal darkness, it carries implications of universal illumination. In "When the Dumb Speak," Bly describes

$$
\begin{aligned}
& \text { E. a joyful night in which we lose } \\
& \text { Likerything, and drift } \\
& \text { Rising adish } \\
& \text { At last throws us, into the ocean }
\end{aligned}
$$

One ocean flows from the waters of inner experience described throughout much of Silence, but the other spreads through time as well as space. "When the Dumb Speak" ends with "images" which evoke traditional Christian visions of the world ending in apocalypse.

Images of the body shaken in the grave,

And the grave filled with seawater;

Fires in the sea

The house fallen,

The gold sticks broken,

But "Evolution from the Fish," as its title indicates, describes what is to come not as a Christian end but as an evolutionary change which parallels earlier changes. Here the loss of "everything," which is a loss of self, becomes a participation in the physical development of life from the beginning. "The grandson of fishes" is described

. . moving toward his own life

Like fur, walking. And when the frost comes, he is

Fur, mammoth fur, growing longer

He moves toward the animal, the animal with furry head!

As the poem moves into our time the furry-headed one becomes specific, indi- 
vidual, "this long man with the student girl," but in the end he is embarking on another voyage, in darkness, through sleep.

Serpents rise from the ocean floor with spiral motions,

A man goes inside a jewel, and sleeps. Do

Not hold my hands down! Let me raise them!

A fire is passing up through the soles of my feet!

An earlier version of "Evolution" appeared in 1962 in a brief anthology of poems by Bly, Duffy, and Wright, The Lion's Tail and Eyes. Indicatively, it included one additional last line: "I am curving back into the mammoth pooll" By omitting the backward curve Bly alters the final direction of the poem from the past to the future; now the subject is not repeating cycles of existence but a continuing upward spiral into new states of being.

Bly is at his most difficult, to follow and to accept, when he begins to describe the particular nature of the apocalypse to come, and the evolution it heralds. A premonitory poem in Light, "Romans Angry about the Inner World," describes that world as "A jagged stone/ Flying toward them out of the darkness" and suggests the final articulation of Bly's evolutionary vision. In the poem "executives" watch Roman executioners torture "a woman/ Who has seen our mother/ In the other world." Specifically the lines refer to the mystical cult of Magna Mater, eventually suppressed by the Romans. But the anachronistic presence of the executives implies a comparison between imperial Rome and neoimperialist America, a comparison that goes beyond ordinary politics. Later Bly will elaborate the theory that the mother-goddesses smothered by one empire are returning to haunt the psyche of the other. In his long introduction to "The Teeth Mother Naked at Last" at the Antioch reading, Bly explained a vision of mythic development largely based on the psychological and historical investigations of Jung's disciple Erich Neumann. Originally, as Bly explains Neumann, the world's great religions were based on worship of the female principle, the Great Mother; the Romans and the Jews fought to substitute male gods for the female goddesses, beginning the long western tradition of primacy of the masculine consciousness. Bly defines sexual consciousness in Jungian terms: masculine consciousness involves logic, efficiency, the advancement of material civilization, repression, and control of the natural world; and feminine consciousness involves intuition, creativity, mystic acceptance of the world. Because only women are biologically creative, it is usually the man who feels the aesthetic urge to create with materials outside his own body. However he is truly inspired only if he makes "the great turn" toward the mother, accepting the guidance of the (always female) Muse, and exploring his own feminine consciousness (Jung's anima). Now, though, not only artists but the whole culture is beginning, psychologically, to turn to the Great Mother. "America looks down in the psyche now," Bly said at Antioch, "and it sees the mothers coming up." "That's what's been happening in America in the last fifteen years, that the father consciousness civilization is dying and the mothers are returning." 
As the mythic forms of the mothers suggest, this can be a destructive as well as liberating process. Drawing on various mythologies for examples Bly describes the four great mothers in opposed pairs, constructive and destructive: the mother of fertility (Demeter) balanced by the mother of destruction (Kali), the ecstatic mother (Artemis) balanced by the stone mother (Medusa). In this relation to each other they form a cross, or the four main compass points of a circle, and the teeth mother hovers on the circumference between death and stone mothers. To prove his theory, Bly cites widely various bits of evidence of the return of the different mothers. One manifestation of the destructive mothers in the aesthetic consciousness appears, for instance, in deKooning's paintings; Bly is perhaps thinking of works like "Woman I." In a very different sphere, Bly attributes the American violence of Vietnam, often directed against women and children, to our pathologically masculine soldiers' fear of the female, of the mothers, whom they see only in the form of the death mother or the teeth mother. On the other side, Bly sees in hip and liberated life styles the influence of the ecstatic mother, though he explains that the search for the ecstatic mother can fail in a long fall toward the stone mother-the use of drugs, too, dramatizes this paradox, and Bly the comedian does not hesitate to play on the colloquial sense of "stoned."

To those moved by the visionary qualities of Bly's poetry, this theory may present serious problems. How much of it is really believable, how literally does Bly intend it, how necessary is it as a basis for his poetry? Indicatively, little of the theory actually appears in "The Teeth Mother Naked at Last," though it provides a striking title. Bly's vision of the great evolutionary change is felt more convincingly in his poetry-explorations into "the inward world . . . thoughts we have not yet thought" which involve little detailed reference to the mothersthan in his spoken and very explicit explanations of what he thinks now. Bly the performer is enormously compelling, a constantly disarming mixure of vaudeville comedian and oracle, but in retrospect, beyond the range of his personal vibrations, his archetypal sociology does not fully convince. Perhaps in our time any extreme definition of the opposition between male and female consciousness must seem suspect. More important, though, is the tension between Bly's use of the old Jungian archetypes to describe our future, and the constant suggestions in his poetry that the present movement of human consciousness is something new, now hardly dreamed of. Somehow it seems inadequate to describe "the body not yet born" in terms of ancient myths, however they are blended or transmuted to define the world to come. Better to accept Bly's explanations as metaphor, his poems as reality.

For it is the sense of deeply perceived reality in the poetry that leads us in the first place to consider the prose articulation of the theory, and in fact Bly the poet, as he points out, was using the conflict between "masculine" and "feminine" as a metaphor long before he read Neumann and developed his theory. In Light, for instance, "The Busy Man Speaks" defines "the mother" in terms of "art," "sorrow," "the ocean;" and "the father" in terms of "The stones of cheerfulness, the steel of money." Still earlier, in Silence, women are often associated with liberating death, as in "With Pale Women in Maryland:" "Like those before, we move to the death we love/ With pale women in Maryland." 
To see Bly's poetry as dependent on anyone's theory, on Jung's, Neumann's, or even Bly's own, is not only to deny his belief in the irrational psychic sources of poetry but also to dilute the unique force of his poems. If we turn to Jung for explanations, we can say simply that the origin of Bly's deep images is the collective unconscious, that the conflict between the inner and outer worlds is a conflict between anima and persona, that Bly's water imagery is, given his concerns, predictable. Water, Jung says in "Archetypes of the Collective Unconscious," is "no figure of speech, but a living symbol of the dark psyche," the realm "where I experience the other in myself." Even Bly's paradoxical discovery of vitality in death can be explained in terms of Jung's contention, in "Psychological Aspects of the Mother Archetype," that "Nothing can exist without its opposite; the two were one in the beginning and will be one again in the end. Consciousness can only exist through continual recognition of the unconscious, just as everything that lives must pass through many deaths." But to interpret Bly basically in these terms is to oversimplify his paradoxes without really explaining them, as Jung's archetypes inevitably tend to reduce and oversimplify complex individual states of being. Descending into realms initially explored by Jung and later by Neumann, Bly goes beyond both. His greatest strength is his ability to discover in the darkness images that are not archetypal, at least not in the Jungian sense, because they are only beginning to loom into view.

But even if we remain unconvinced by the details of Bly's theory we cannot deny that it remains a fascinating metaphor for states as yet not analytically describable. More important, the mothers metaphor enables Bly to develop and enrich the paradoxes that float up from his inner darkness. He has constructed a vision of mystic evolution that not only refuses to deny but explains the moral dissolution that forms the primary vision of Light. The tension between the ecstatic mother and the stone mother provides a theoretical basis for Bly's double conception of darkness, the inspiring darkness of the inner world held in suspension with the terrifying blackness of the outer. "The Teeth Mother Naked at Last," a map of the psychological politics behind an imperial war, is also a record of the collision between inner and outer worlds.

"Teeth Mother," though marked throughout by Bly's characteristic surrealist imagery, differs basically from his earlier poetry. So far it is his only really extensive poem, and its coherence is more theoretical than imagistic. Frequently its deep images give way to flat, almost prosy statement, often far less striking than the visions of Light, but in some ways more moving. Bly adopts different tactics in this poem partly because he is writing a sort of propaganda based on juxtaposition of certain facts, but also because it seems impossible, and probably not desirable, to assimilate the actuality of Vietnam into poetry as Bly has previously written it. The Vietnam poems in Light primarily concerned the reverberations of war; "Teeth Mother" is often a simple contemplation of unbearable facts. But it also implies an explanation.

Helicopters flutter overhead. The death-

bee is coming. Supersabres

like knots of neurotic energy sweep 
around and return.

This is Hamilton's triumph.

This is the advantage of a centralized bank.

Destructive-"neurotic"-machines dominate the poem; despite his moral revulsion, Bly's ability to immerse himself in things enables him to evoke the alien world of machines and mechanical men as fully as he evokes the inner world. Vietnam represents the desperate end of the "masculine" rage for order, the force that created American prosperity but a force basically corrupted by its denial of the inner world. The warrior mentality, recreating itself in machines, opposes not only nature (" 800 steel pellets fly through the vegetable walls") but the dark flow of its own humanity, its movement toward the death which completes life. The desire for death as fulfillment, corrupted, becomes a desire for death as grotesque destruction.

The ministers lie, the professors lie, the television lies, the priests lie...

These lies mean that the country wants to die.

It is a desire to take death inside,

to feel it burning inside, pushing out strong hairs,

like a clothes brush in the intestines

In a series of awkward but often striking juxtapositions, Bly suggests that the American rejection of grief and darkness, made possible by wealth, creates the grief of Vietnam. It is:

because we have so few tears falling on our own hands

that the Supersabre turns and screams down toward the earth

In the face of this there appears no adequate response, no praise of the grief that follows the denial of grief, no mystical acceptance. Bly the political moralist presents, ironically undercut, the plea of the contemplative dreamer, who sees the corporeal flow of existence very much in terms that suggest Silence.

Tell me about the particles of Babylonian thought that still pass through the earthworm every day,

Don't tell me about "the frightening laborers who do not read books"

But the dehumanizing outer darkness prevails:

if one of those children came near that we have set on fire, came toward you like a gray barn, walking, you would howl like a wind tunnel in a hurricane you would tear at your shirt with blue hands, 
No response to this, and yet, paradoxically, Bly suggests a response, or at least a way of understanding it. The horribly catalogued violence against human and vegetable nature can be seen in a more distant sense as a natural aspect of the apocalyptic evolutionary change described in more positive terms in the final pages of Light. One voice in "Teeth Mother," looking for solace, suggests of the violence of "the Marine battalion," "This happens when the seasons change/ this happens when the leaves begin to drop from the trees too early." Bly undercuts the suggestion of solace, but the comparison remains. Vietnam, in some sense the death of American dreams, is not an end but a transition, in which the teeth mother necessarily appears as an aspect of the ecstatic mother.

Now the whole nation starts to whirl

pigs rush toward the cliff,

the waters underneath part: in one ocean luminous globes

float up (in them hairy and ecstatic rock musicians)in the other, the teeth mother, naked at last.

The balance, and the sense of cycles evolving, provide no cure to present agony. Bly knows it is the false transcendence of agony, with its attendant repression, which distorts human consciousness in the first place. But the vision of evolution enables Bly to sustain his paradoxical suspension of despair and mystic hope, his sense of death as life. Perhaps that paradox will always defy resolution, but in his latest poetry Bly continues to offer hope for evolution into a state of consciousness in which despair can be replaced by that grief which attends the natural movement of life, which is not inconsistent with joy. At the end of a recent poem read at Antioch, Bly suggests, through paradox now expressed with a clear simplicity, that the conflict between the father and the mother may be resolved by that consciousness now being born.

More of the fathers are dying each day,

It's time for the sons.

Bits of darkness are gathering around the sons,

The darkness appears as flakes of light.

\section{SO MUCH IS NOT SPOKEN}

Oh yes, I love you, book of my confessions, when the swallowed begins to rise from the earth again, and the deep hungers

from the wells. So much is still inside me-like cows eating in a collapsed strawpile all winter to get out.

Everything we need now is buried, it's far back into the mountain, it's under the water guarded by women. 